\title{
Application of Electric Information Acquisition and Analysis Platform in Energy Saving and Reducing Loss
}

\author{
Xinze JIANG ${ }^{1,}$, , Lifang WANG ${ }^{1,}$, , Chengshuo $\mathrm{HE}^{1, \text { a }}$, Yuefeng $\mathrm{GU}^{2, \mathrm{~b}}$, Lizong \\ WANG ${ }^{3, c}$, Chengzhe DONG ${ }^{3, c}$ Wenxin $\mathrm{HAN}^{3, c}$

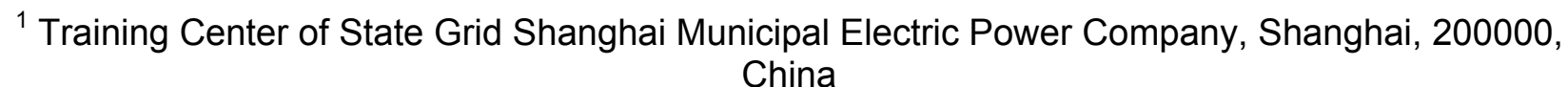

${ }^{2}$ North Power Supply Company of State Grid Shanghai Municipal Electric Power Company, Shanghai, 200000, China

${ }^{3}$ Beijing Greenergy Electric Technology Co.,Ltd, Beijing, 100000, China

aemail: 13003108191@126.com, bemail:cjiaml@163.com, cemail:47407349@qq.com

\begin{abstract}
Keywords: Electric Information Acquisition Platform; SG186 System; Marketing Analysis; User Monitoring
\end{abstract}

\begin{abstract}
With the development of market economy, the management system of power supply enterprise gradually improved, and the "line loss rate", which affects its comprehensive technical and economic indicators, is becoming increasingly significant, especially driven by the interests, criminals use a variety of high-tech methods to steal electricity than caused the high rate of line loss. In this paper, a method that analysis the user exception data and monitor the key users using electricity information acquisition and analysis platform based on SG186 system is proposed. This method provides a guarantee to achieve the goal of the user's electricity information management and building a green grid.
\end{abstract}

\section{Introduction}

The on-line operation of SG186 marketing business system preliminary achieve the "big marketing" management module and make technical basis for the lean management. However, the system lacks the powerful anomaly analysis, user monitoring and other functions. It is difficult to find the abnormal user by analyzing large amounts of user information. The electric information acquisition and analysis platform can solve this problem. The electric information acquisition and analysis platform can collect the power information automatically, monitor the abnormal statement, analysis the electrical usage and management capabilities. It can quickly analyze the electricity information by various conditions to find the abnormal statement and provide support for marketing decisions. This paper discusses the application of electric information acquisition and analysis platform in energy saving and reducing loss from analysis abnormal electricity and key users monitor.

\section{Electric Information Acquisition and Analysis Platform}

The electric information acquisition and analysis platform is an important component of smart grid. It enables online monitoring and real-time information collection of the user load, power, voltage and other import information, and this provides a basis for the SG186 information system timely, completely and accurately. It can also provide a technical basis for the implementation of marketing core business, such as remote automatic meter reading, real-time calculation of line loss. So as to provide technical support for the analysis of the decision-making power, enhance the response capability of market changes, customer needs and the state of user's power state[1][2]. The user's electricity information from electricity information acquisition system can provides important basic data in demand-side management, key user analysis, line loss management and illegal usage of electricity management, customer service, power quality monitoring, power market analysis and other expanding types of business [3][4][5]. Base on this information, we can carry out a variety of 
statistical analysis and provide base data and decision-making basis for the company's management decisions.

\section{Analysis of Abnormal Electricity Usage}

With the full coverage of smart meter, the measurement accuracy was improved and enriching the comprehensive state of energy indicators, providing a variety of ways for the metering devices working state judgments. At the same time, the measurement error caused by failure of the electronic components can't be avoided [6] [7] [8]. Currently, deterring and providing effective data support for this case are as follows:

(1) Invalid data

If the total number of timeshare is not equal to the total number of all the time, the data is regarded as invalid. We can calculate the real value by reading the memory value.

Taking the No.0100012345 user for instance in one city, the energy used in June and July is 6878.58 which is the same, thus, the total power the user used in July is 0 . When the staff read the value in the memory, they found that the real value is 7563.43 , and the active power is 7557.10 . From the data analysis, they found the invalid meter data. The active power flow is shown in figure 1.

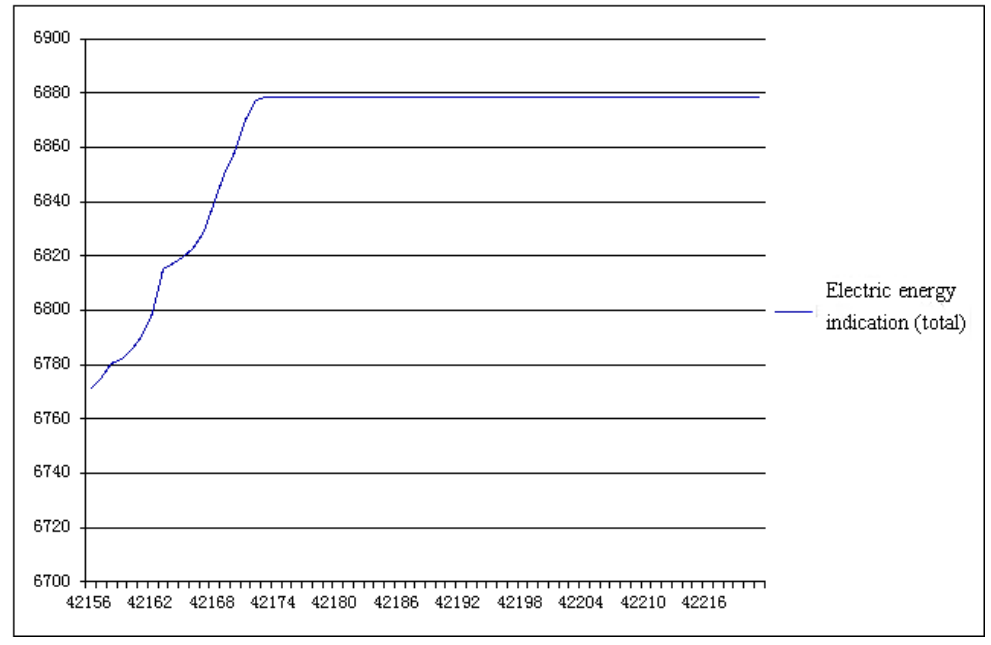

Fig.1. the Electric Power Data

(2)Reverse number abnormalities

Reverse number abnormalities refers to the phenomenon that the reverse active energy is in an overrun growth state. This problem is caused by the reverse wiring errors, and the reverse power is greater than the positive power and ultimately affects the marketing billing.

Taking one user for instance in one city, the detail data is as follows:

\begin{tabular}{|c|c|c|c|c|}
\hline Phase & Active power $/ \mathrm{kW}$ & Power factor/\% & Voltage/V & Current/A \\
\hline Sum & -0.0269 & 62.4 & 99.8 & 0.18 \\
\hline A & 0.0265 & 63.9 & 101 & 0.41 \\
\hline C & 0.0534 & 100 & 102 & 0.52 \\
\hline
\end{tabular}

Tab.1. the detail data for reverse number abnormalities 
From table 1, we find that the total power equals to active power of phase A minus active power of phase $\mathrm{C}$. The electricity inspectors found that the $\mathrm{C}$ phase of the meter is reversed by site inspection. Finally, the retroactive charge is $21232 \mathrm{~kW} \cdot \mathrm{h}$.

(3)Power factor abnormalities

In recent years, with the ongoing efforts to combat stealing electricity, the way that the stealing electricity is from the simple and crude gradually to more complex hidden, which by changing the meter wiring, disrupting the phase sequence and phase relationships of stealing method gradually increased. Taking one user for instance in one city in 2014,there are 7 users stealing electricity in this way among the 13 users, accounting for $54 \%$, the following figure shows the information the system collected.

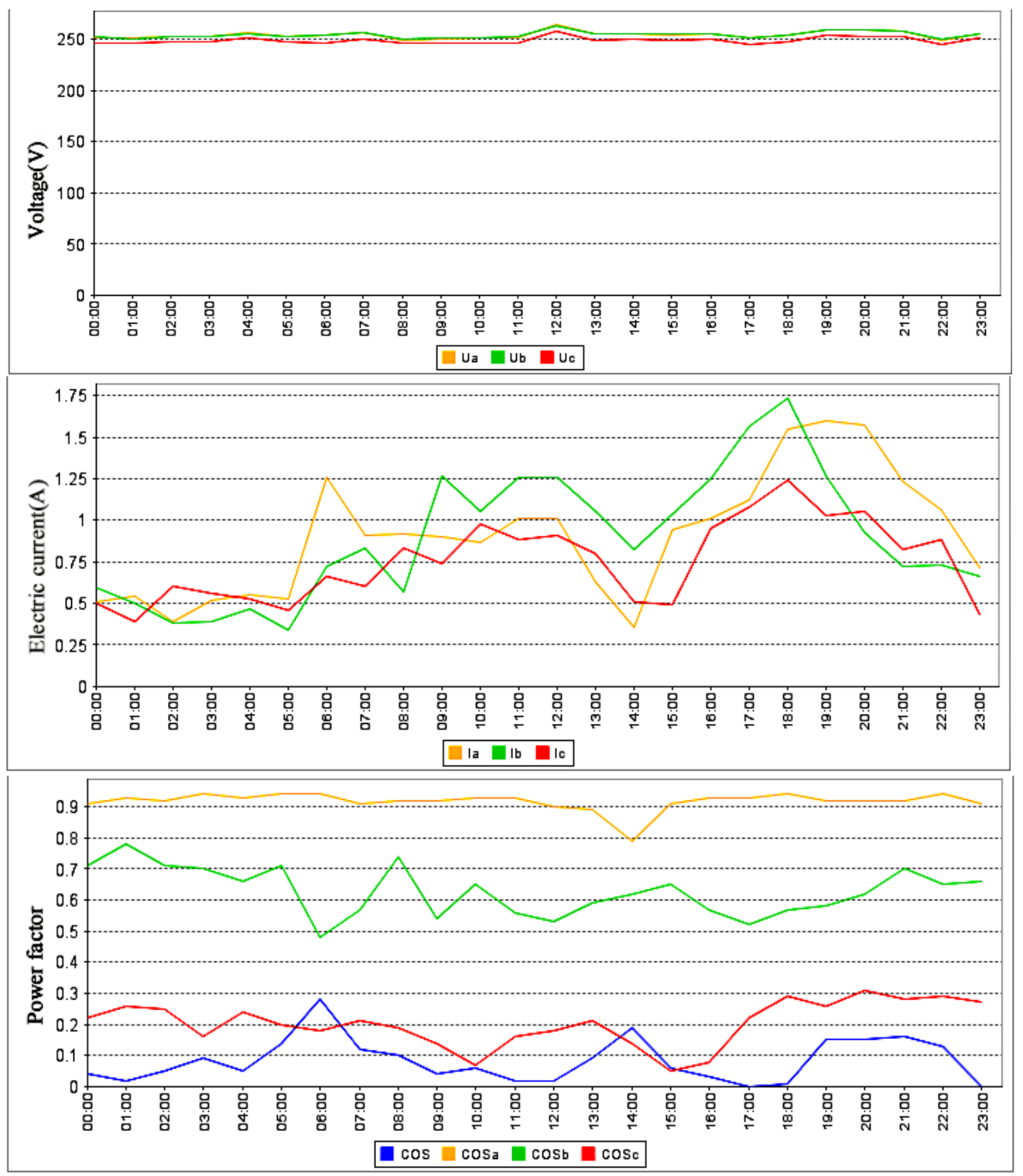

Fig.2. the Electric Power Data of One User in Shanghai

As can be seen from the figure that the user's current and voltage is normal, however, B, C phase and total power factor is low. By on-site inspection, the staff found that the phase of current and voltage is reversed, thereby, achieving less power measurement purposes.

There are other stealing electricity ways, such as abnormal voltage and current measured by the meter, clock abnormal, power reverse, monthly electric power abnormal, meter stopping going, and low battery. 


\section{Analytical method}

We can find the abnormal electricity state by taking collect data for comparison, statistical analysis. For example, we can compare to the data in the same measurement points in different collection methods.

In the actual processing and circulation problems during the following process flow, seen in figure 3 .

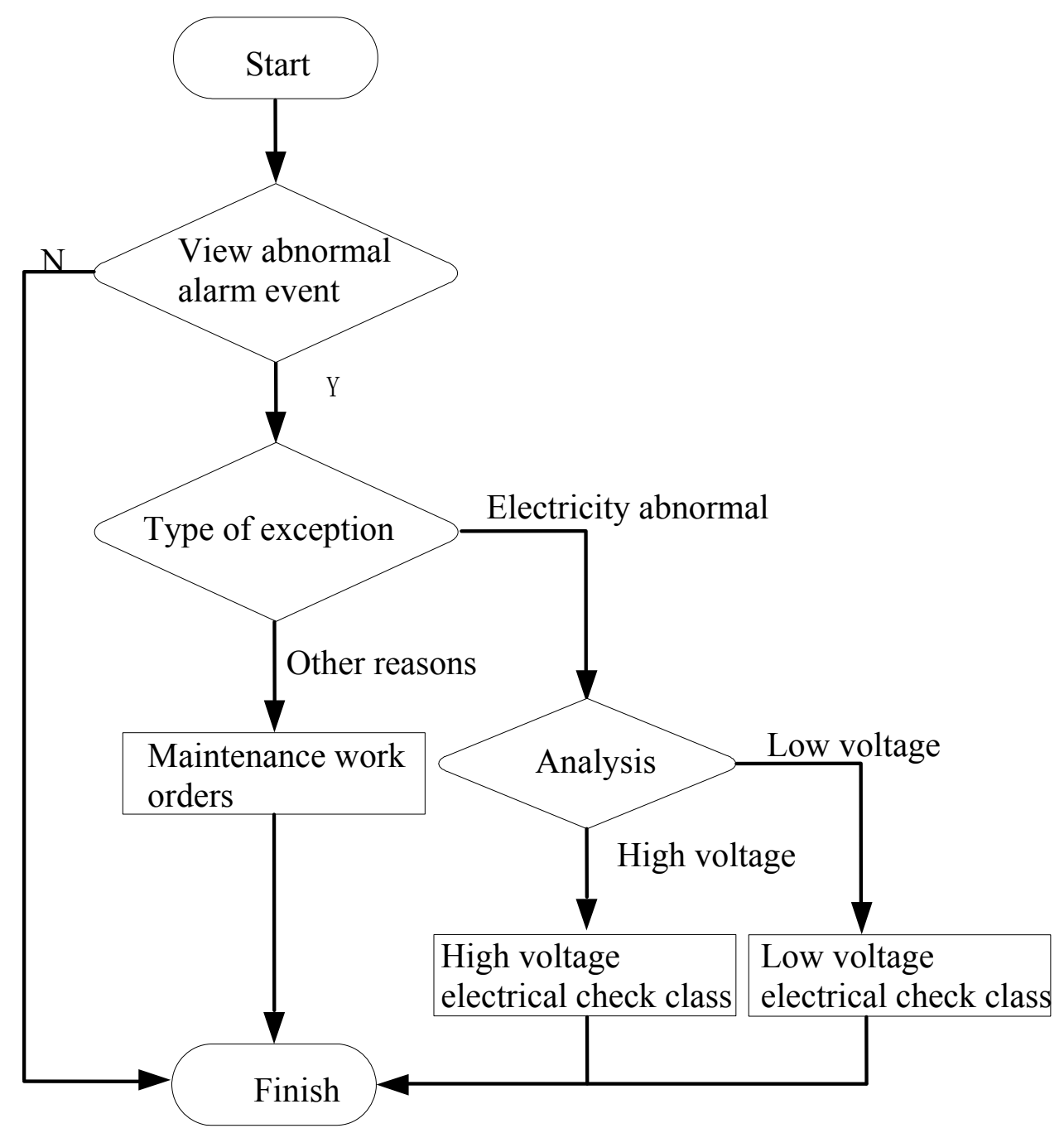

\section{Key User Monitoring}

We can provide query, analysis capabilities and tracking of the electricity users. The key users can be classified according to the definition of business combination, capacity, voltage rating, and price category and so on. The query information includes historical and real-time load curves, electrical energy curve, power quality data, condition data and information and other unusual events. Analyzing and monitoring the key users is focus on the following aspects.

(1)Business Analysis

One of the way to make business analysis is to compare to the data of line losses, or power between this year and a year earlier or horizontal contrast between the power station and different regions or comparing to the whole history data of the company each month and a variety of accounting reports.

(2)Load analysis of stage area

The system automatically calculates full load hours of all stage area, and sets the full load hours in descending orders. This process provides information to determine the overload stage area.

The full load hours equals to power supply capacity dividing the station area capacity. If the full load hours are more than 350, it is regarded as in overload condition. If the full load hours are 
more than 500, it may not match the reality.

(3)Unbalanced analysis

The problem of unbalanced phases will cause the increasing line loss, zero line blown easily, line voltage decreasing of the end users. The system can automatically calculate the three-phase unbalanced ratio according to the ABC three-phase power of each station area and descending order. This provides the basis for reducing line losses for adjusting three phases balanced.

(4)Energy power analysis

We can analyzing the collecting data by region, industry, line, voltage level, custom groups, users and other categories in time dimension such as day, month, quarter, year or period and so on. It is including statistical electric energy inquiry, electrical energy up the chain analysis, peak analysis, mutation analysis of electric energy, ranking analysis and so on.

(5)Load analysis

We can analyze the load in combination way by region, industry, line, voltage level, custom groups, and other types. We can calculate the maximum load of statistics and time of occurrence, time of the minimum value occurrence, the load curve trends and comparing the same period in order to keep abreast of the changes in system load.

\section{Conclusion}

Currently the superiority of the electricity information acquisition and analysis platform could have been fully reflected, and the reasons for line losses can be analyzed by the collecting data. We can implement appropriate control programs to improve the line loss management, reducing the power loss, combating the stealing behavior effectively and making a contribution for the construction of green power grid.

\section{References}

[1] Peizhong Diao. Application of electric information acquisition and analysis system in electric power enterprise. China Electric Power Education[J], Beijing 2002,254-257.

[2] Limin Zhang. Application of electric information acquisition and analysis system in demand-side management. China Electric Power Education[J], Beijing 2011,36-39.

[3] Chan M H L, Donaldson R W. Amplitude, width, and intrerarrival Distributing for noise impulses on introbuildding power line communication-works[j],IEEE Transaction on EMC, 2006:34-48

[4] Smith H L. DA/DSM directions. An overview of distribution automation and demand-side management with implications of future trends [J]. Computer Applications in Power, IEEE, 1994,7(4):23-25

[5] Meissner E, Richter G. Battery monitoring and electrical energy management; Precondition for future vehicle electric power systems[J].Journal of power sources,2003,116(1):79-98

[6] Bearden M K, Jenrette W I, Randall B E. Electrical energy meters having real-time power quality measurement and reporting capability: U.S. Patent 5,627,759[P].1997-5-6

[7] Rogai S. System for the remote data acquisition and control of electric energy meters: U.S. Patent 7,271,735[P].2007-9-18

[8] YU C, XIE J. The Application of Winsocket Technology in the Design of a Remote Power Supervising and Control System [J]. COMPUTER ENGINEERING, 2000, 10:034 